\title{
PENGARUH WORK LIFE BALANCE DAN KETERIKATAN PEGAWAI TERHADAP KINERJA PEGAWAI FAKULTAS ILMU SOSIAL DAN ILMU POLITIK UNIVERSITAS INDONESIA
}

\begin{abstract}
Maya Sarikit*
Abstract: The objective of the research is to obtain information about the influence of work life balance and employee engagementon employees job performance onFaculty of Social and Political Sciences of the University of Indonesia. The research was conducted to all of employees onFaculty of Social and Political Sciences of the University of Indonesia by using a survey method with path analysis applied in testing hypothesis. The number 67 employees as sample was selected by using Slovin formula. The result of the study reveals that: (1) there is direct effect of work life balance on job performance. (2) there isdirect effect of employee engagement on job performance. (3) there is direct effect of work life balance on employee engagement. Therefore to enhance employee's job performance can be carried out by work life balance, and employee engagement.
\end{abstract}

Keywords: Work life balance, employee engagement,andjob performance

\section{PENDAHULUAN}

Perguruan tinggi merupakan salah satu bentuk dari organisasi. Sebagai penyedia jasa pendidikan, perguruan tinggi berperan besar dalam menyukseskan program pemerintah yaitu mencerdaskan kehidupan bangsa. Ketatnya persaingan antar perguruan tinggi membuat perguruan tinggi harus memperhatikan kualitas lulusannya agar tetap mampu bersaing dengan perguruan tinggi lainnya. Sebagaimana layaknya organisasi, lembaga pendidikan mempunyai kelengkapan unit-unit organisasi, seperti; Direktorat, Fakultas, Departemen, Program Studi, dan Unit Pelaksana Teknis, lainnya yang semuanya bertanggung jawab untuk dapat terselenggaranya proses belajar mengajar secara baik dan lancar.

Fakultas, sebagai salah satu unsur penunjang dari suatu universitas, menjadi sangat penting peranannya karena berkewajiban untuk dapat melaksanakan penyelenggaraan aktivitas akademik secara tertib, tepat waktu dan lancar, seperti penyelenggaraan belajar mengajar, riset dan publikasi, pengabdian kepada masyarakat, pelayanan administrasi akademik, kerjasama-kerjasama dengan pihak luar dan alumni untuk pengembangan pendidikan. Adapun salah satu tugas utamanya adalah memberikan pelayanan administrasi akademik kepada para mahasiswa, dosen dan pengguna lainnya. Dalam upaya meningkatkan kualitas layanan pendidikan pada perguruan tinggi, maka fakultas dituntut untuk mampu meningkatkan kinerja dalam melayanani kepada para pengguna (user),sejalan dengan tuntutan perkembangan perguruan tinggi pada umumnya, dan pengembangan Ilmu pengetahuan yang demikian cepat dewasa ini.

* Pegawai Fakultas Ilmu Sosial dan Ilmu Politik, Universitas Indonesia 
Dalam mencapai visi dan misinya, fakultas menginginkan kinerja yang memuaskan. Hal ini menuntut kreativitas, integritas dan komitmen dari tim dalam fakultas untuk memaksimalkan diri dengan kompetensi yang dimiliki untuk bersama-sama mencapai tujuan organisasi yang sudah disepakati.Kinerja yang baik akan menghasilkan hasil yang memuaskan, namun sebaliknya kinerja yang buruk akan menghasilkan hasil yang buruk pula. Hal ini menjadi perhatian khusus dalam fakultas, bagaimana pencapaian tujuan yang efektif melalui kinerja yang baik.

Dukungan dari pimpinan fakultas sangat penting dalam upaya meningkatkan kinerja pegawai. Dukungan berupa akses informasi dan peningkatan kompetensi akan sangat membantu kinerja tim menuju kualitas dan kuantitas pegawai dalam mencapai hasil yang optimal. Dukungan informasi yang dimaksud di sini adalah berupa informasi yang terbaru dan teraktual menyangkut kepentingan organisasi, sehingga menjadi gambaran kedepannya bagaimana mensinergikan beragam pekerjaan organisasi yang baik kedepannya. Sedangkan kompetensi yang dimaksudkan disini yaitu berupa sinergisnya keterampilan, ilmu pengetahuan dan pengalaman dalam melaksanakan tugas - tugas yang diberikan.

Banyak cara yang dapat digunakan untuk menciptakan sumber daya manusia yang memiliki kompetensi inti.Dalam melakukan pengembangan pegawai, salah satu caranya adalah dengan membekali mereka dengan kemampuan profesional dan teknis, berinvestasi dalam pelatihan dan pengembangan para pegawai tersebut. Kompetensi yang harus dimiliki oleh sumber daya manusia dalam organisasi adalah: memiliki produktivitas, inovasi, ketrampilan khusus, sehingga pegawai memiliki kualifikasi yang memadai dan mampu memberi pelayanan yang memuaskan. Disamping itu juga perlu diketahui faktor-faktor psikologis yang ada pada pegawai, seperti masalah keseimbangan kehidupan kerja dan di luar kerjanya. Kemampuan pegawai dalam menyeimbangkan kehidupan pribadi, sosial dan individunya dapat memberikan dampak pada kinerjanya. Keterikatan kerja menjadi salah satu prediktor yang sangat signifikan yang mempengaruhi kinerja pegawai. Hal ini perlu dipahami oleh pimpinan fakultas karena penentu keberhasilan dan pencapaian tujuan organisasi selalu berkaitan dengan sumber daya manusianya. Hal tersebut membuat sikap kerja pegawai menjadi hal yang penting untuk diperhatikan oleh organisasi.

Salah satu sikap kerja yang memberikan kontribusi terbaik untuk peningkatan kinerja pegawai adalah keterikatan pegawai. Keterikatan merupakan ekspresi yang dikehendaki seseorang berkaitan dengan perilaku tugasnya, yang menghubungkan pekerjaannya dengan eksistensi personal (fisik, kognitif, dan emosional) dan peran diri secara utuh. Dimensi fisik, kognitif, dan emosional merupakan energy yang mampu mendorong seseorang untuk bekerja secara optimal, sedangkan peran diri tergambar melalui kondisi psikologis. Dimensi fisik, kognitif, dan emosional diungkapkan melalui ekspresi diri menunjukan identitas, pemikiran, dan perasaan sesungguhnya dalam meningkatkan kinerja. 
Dalam lingkup organisasi Fakultas Ilmu Sosial dan Ilmu Politik Universitas Indonesia, terdapat beberapa masalah yang menunjukan kinerja pegawai masih kurang optimal, diantaranya; kurangnya pemberian pelayanan yang memuaskan kepada mahasiswa dan stakeholder, masih terdapat pegawai yang datang terlambat ke tempat kerja. Masih kurangnya kerjasama tim di lingkungan kerjanya, masih adanya pegawai yang mengulur-ulur waktu dalam bekerja, dan melaksanakan pekerjaan tidak tepat waktu.

Penilaian kinerja adalah salah satu tugas penting untuk dilakukan oleh seorang manajer atau pimpinan. Walaupun demikian, pelaksanaan kinerja yang optimal bukanlah tugas yang sederhana yang bisa dengan mudah dilakukan oleh karyawan atau seorang manajer. Oleh karena itu, menjadi penting untuk mengetahui kepribadian dari individu yang berdampak langsung pada organisasi. Hal ini perlu dilakukan untuk menjaga kinerja organisasi dalam menjalankan aktivitasnya. Mempelajari perilaku manusia sebagai individu, sebagai anggota kelompok dan sebagai anggota organisasi secara keseluruhan sangat berkaitan dengan efektivitas pencapaian tujuan organisasi.Kinerja pegawai adalah faktor yang mempengaruhi seberapa banyak mereka memberi kontribusi kepada organisasi. Perbaikan kinerja baik untuk individu maupun kelompok menjadi pusat perhatian dalam upaya meningkatkan kinerja organisasi. Peran dari para pegawai, khususnya tenaga administrasi tidak dapat diabaikan begitu saja, karena keterlibatan mereka cukup banyak dan sangat tinggi frekuensinya dalam mendukung kelancaran penyelenggaraan proses belajar mengajar pada suatu perguruan tinggi atau lembaga pendidikan.

Berdasarkan uraian di atas, unit-unit kerja pelaksana teknis dan administrasi akademik di fakultas atau dalam hal ini pada pegawai Fakultas Ilmu Sosial dan Ilmu Politik Universitas Indonesia dituntut untuk meningkatkan kinerjanya agar FISIP UI tetap mampu bersaing dengan perguruan tinggi lainnya yang ada di Indonesia secara nasional. Salah satu faktor yang diduga berpengaruh terhadap kinerja pegawai Fakultas Ilmu Sosial dan Ilmu Politik Universitas Indonesia adalah work life balance dan keterikatan pegawai.

Colquitt, Lepine dan Wesson (2013:33) menjelaskan, "job performance is formally defined as the value of the set of employee behaviors that contribute, ether positively or negatively, to organizational goal accomplishment". Kinerja secara formal didefinisikan sebagai nilai dari berbagai perilaku karyawan yang berkontribusi, baik positif atau negatif untuk mencapai tujuan organisasi.

Selanjutnya James L.Gibson, et.al(2012:374) menjelaskan, "job performance is the outcomes of jobs that relate to the purposes of the organization such as quality, efficiency, and other criteria of effectiveness". Kinerja adalah hasil dari pekerjaan yang berhubungan dengan tujuan organisasi, seperti kualitas, efisiensi, dan kriteria efektivitas lainnya.

MenurutLloyd (2011:214) menjelaskan, "job performance is the net effect of an employee's effort as modified by abilities and role (or task) perceptions". Kinerja adalah efek bersih dari upaya karyawan yang dimodifikasi oleh kemampuan dan peran (atau tugas) persepsi. Kemudian kinerja menurut Schermerhorn (2005:368), "job 
performance is measured as the quantity and quality of task accomplished by an individual or group". Kinerja diukur sebagai kuantitas dan kualitas tugas yang dicapai oleh individu atau kelompok.

Jex dan Britt (2008:96) mengatakan, "job performance is a deceptively simple term. At the most general level, it can be defined simply as all of the behaviors employees engage in while at work".Kinerja seakan -akan sebuah istilah sederhana, pada tingkat yang lebih umum, kinerja dapat didefinisikan secara sederhana sebagai keseluruhan perilaku pegawai yang terlibat sementara dalam bekerja. Lebih lanjut lagi Jex dan Britt mengatakan kinerja tidak hanya terbatas pada perilaku pegawai yang berhubungan dengan kinerja tugas, akan tetapi juga berhubungan dengan tugas dan tanggung jawab pegawai terhadap tugasnya.

Katherine Lockett (2008:26-27)) menjelaskan, "work/life balance is the need of all individuals to achieve and maintain a balance between their paid work and their life outside of work. The word balance doesn't necessarily imply an even divide between work and life; instead, balance means successfully managing all the responsibilities you have in both areas of your life". Work life balance merupakan sesuatu yang dibutuhkan setiap individu untuk diraih dan dikelola secara seimbang antara kehidupan kerjanya dan kehidupan di luar pekerjaan. Kata seimbang disini tidak selalu berarti bahwa membagi antara pekerjaan dan kehidupan sehari-hari, sebaliknya keseimbangan berarti berhasil mengelola semua tanggung jawab yang dimiliki di kedua kehidupan pegawai.

Selanjutnya Katherine Locket (2008:26-27) mengemukakan bahwa, "achieving work/life balance isn't about being given the opportunity to have some control over when, where and how you work so that you can perform at your best and also have time to recuperate and enjoy pursuing your own interests outsides of work". Untuk mencapai work life balance adalah dengan memberikan kesempatan untuk memiliki kontrol atas kapan, di mana dan bagaimana seseorang bekerja sehingga dapat melakukan yang terbaik dan juga memiliki waktu untuk memulihkan diri dari mengejar kepentingan diri sendiri di tempat kerja dan kehidupan.

Senada dengan penjelasan di atas, Bloombury (2005:2-3) menjelaskan, "worklife balance is a feeling of being in control of your life, being able to exercise choice, and about finding an equilibrium between your own needs and those of others, whether at work or at home". Work-life balance adalah kendali seseorang dalam kehidupan keluarga dan pekerjaan, kemampuan menyeimbangkan antara tanggung jawab kerja dan di luar pekerjaan, dan menemukan keseimbangan antara kebutuhan sendiri dan kebutuhan orang lain, baik di tempat kerja maupun di rumah.Dengan kata lain seorang karyawan sangat membutuhkan akan adanya keseimbangan kehidupan kerja yang baik di organisasinya tersebut karena seorang karyawan mempunyai tuntutan yang sangat tinggi, yaitu harus dapat menyeimbangkan hubungan antara pekerjaan yang dituntut harus berjalan sesuai dengan rencana yang diinginkanorganisasi dan kebutuhan akan keluarga juga terhadap diri sendiri, sebagai contoh menjaga kesehatan diri sendiri, memperhatikan perkembangan keluarga, waktu untuk istirahat, berlibur dengan keluarga dan sebagainya. 
Selanjutnya White et al, dalam Delecta, P., (2010:213) menjelaskan, “work life balance as fulfilling the demands satisfactorily in three basic areas of life; namely, work, family and private. Work demands work hours, work intensity and proportion of working hours spent in work. Additional work hours subtract from home time, while high work intensity or work pressure may result in fatigue, anxiety or other adverse physiological consequences that affect the quality of home and family life". Work life balance sebagai pemenuhan tuntutan kepuasan dari tiga kebutuhan mendasar dalam hidup; yaitu, pekerjaan, keluarga dan pribadi, sebuah pekerjaan menuntut jam kerja, intensitas kerja dan proporsi jam kerja yang dihabiskan dalam pekerjaan. Jam kerja tambahan akan mengurangi intensitas waktu yang dihabiskan di rumah, sementara intensitas kerja yang tinggi atau tekanan kerja dapat mengakin=batkan kelelahan, kecemasan atau konsekuensi fisiologis yang akan merugikan kualitas kehidupan di rumah dan kehidupan keluarga.

Work life balance juga didefinisikan sebagai bentuk penyeimbangan antara pekerjaan dan kehidupan pribadi seorang pegawai. Hal ini seperti yang diungkapkan oleh Robert 1. Mathis dan John H. Jackson (2011:124) bahwa, "work life balance: balancing their work and personal lives".

McShane dan Von Glinow (2010:22) menjelaskan, "work life balance is the degree to which a person minimizes conflict between work and nonwork demands". Work life balanceadalah kemampuan seseorang untuk menyeimbangkan antara tuntutan pekerjaan dengan kebutuhan pribadi dan keluarganya.

Katherine Lockett (2008:26-27) menjelaskan, "work/life balance is the need of all individuals to achieve and maintain a balance between their paid work and their life outside of work. The word balance doesn't necessarily imply an even divide between work and life; instead, balance means successfully managing all the responsibilities you have in both areas of your life". Work life balance merupakan sesuatu yang dibutuhkan setiap individu untuk diraih dan dikelola secara seimbang antara kehidupan kerjanya dan kehidupan di luar pekerjaan. Kata seimbang disini tidak selalu berarti bahwa membagi antara pekerjaan dan kehidupan sehari-hari, sebaliknya keseimbangan berarti berhasil mengelola semua tanggung jawab yang dimiliki di kedua kehidupan seseorang.

Stephen P. Robbins dan Mary Coulter(2012:396)menyatakan bahwa, "employee engagement is when employees are connected to, satisfied with, and enthusiastic about their jobs". Keterikatan pegawai merupakan keterlibatan dan kepuasan individu dengan rasa antusias untuk pekerjaannya. Atau dengan kata lain Katerikatan pegawai (employee engagement) merupakan keterilbatan pekerja secara emosional, kognitif dan fisik yang kemudian memotivasi dalam menyelesaikan tugas dengan rasa puas dan antusias.

Senada dengan pernyataan di atas, John R. Schermerhorn, Jr., (2010:72) menjelaskan, "employee engagement is a positive feeling or strong sense of connection with the organization".Employee engagementadalah perasaan positif atau keterlibatan perasaan yang kuat terhadap organisasi dan pada ahirnya akan memiliki antusiasme yang tinggi untuk bekerja. 
Saks dalam Ali Abbaas Albdour dan Ikhlas I. Altarawneh (2014:194) mendefinisikan, "employee engagement is the extent to which an individual is attentive and absorbed in the performance of his/her roles". Employee engagement bukan merupakan sikap, melainkan tingkat dimana seorang individu penuh perhatian dan senang dalam melakukan tugas yang diberikan.

McShane dan Von Glinow (2008:33) menjelaskan, "employee engagement Employees' emotional and cognitive (rational) motivation, their ability to perform their jobs, their possessing a clear understanding of the organization's vision and their specific roles in that vision, and a belief that they have been given the resources to get their jobs done".Employee engagement merupakan bentuk multidimensional yang merupakan keterlibatan pekerja secara emosional, kognitif dan fisik yang kemudian memotivasi dalam menyelesaikan tugas dengan rasa puas dan antusias sebagai kekuatan ilusi yang memotivasi pekerja ke level performa lebih tinggi.

Stephen P. Robbins dan Timothy A. Judge (2013:77) dalam buku Organizational Behavior menjelaskan, "employee engagement is an individual's involvement with, satisfaction with, and enthusiasm for the work he or she does". Employee engagementsebagai bentuk keterlibatan individual dan kepuasannya serta sebagai bentuk antusiasme dalam melakukan pekerjaan.Keterikatan pegawai sebagai kesediaan karyawan, dan kemampuannya untuk berkontribusi dalam kesuksesan organisasi secara terus menerus. Rasa keterikatan terhadap organisasi ini sangat dipengaruhi oleh berbagai faktor seperti faktor emosional dan rasional berkaitan dengan pekerjaan dan pengalaman kerja secara keseluruhan. dan sebagai peran serta dan antusiasme untuk bekerja dengan rasa keterikatan emosional yang positif dan komitmen karyawan.

\section{METODE}

Penelitian ini dilaksanakan di Fakultas Ilmu Sosial dan Ilmu Politik Universitas Indonesia. Sampel yang digunakan adalah Simple Random Sampling dengan jumlah 67 pegawai. Metode yang digunakan dalam penelitian ini adalah metode survey dengan menggunakan kuesioner sebagai alat pengumpulan data pokok dan dokumentasi.

Penelitian ini menggunakan analisis jalur (Path Analysis) untuk mengetahui adanya pengaruh antar variabel sesuai dengan model kausal yang terbentuk. Sebelum kuesioner digunakan dalam penelitian ini terlebih dahulu dilakukan ujicoba untuk menentukan validitas dan reliabilitas instrumen. Hasil tersebut digunakan sebagai instrumen untuk mengambil data penelitian di lapangan. Analisis data meliputi: 1) deskripsi data, 2) uji prasyarat analisis normalitas, 3) analisis jalur yang meliputi: analisis model, pengujian hipotesis dan penentuan tingkat pengaruh. 


\section{HASIL DAN PEMBAHASAN}

\section{Pengaruh Langsung Work Life Balanceterhadap Kinerja}

Dari hasil perhitungan analisis jalur, pengaruh langsung work life balanceterhadap kinerja pegawai Fakultas Ilmu Sosial dan Ilmu Politik Universitas Indonesia. Dari hasil perhitungan diperoleh nilai koefisien korelasi $r_{13}=0,518$ dan nilai koefisien jalur $p_{31}=0.381$. Hasil penelitian ini sesuai dengan kajian yang dilakukan oleh OM Ashtankar (2016:381) yang menyatakan, "from employers point of view, it ensures better insights regarding connections between work life balance and employees' wellbeing, and their impacts on employees' commitment, absenteeism, turnover, productivity and overall performance". Dengan demikian hipotesis 1 yang menduga terdapat pengaruh langsung positifwork life balanceterhadap kinerja pegawaidapat diterima. Hal ini mencerminkan bahwa peningkatanwork life balancemengakibatkan peningkatankinerja pegawai Fakultas Ilmu Sosial dan Ilmu Politik Universitas Indonesia.

\section{Pengaruh Langsung Keterikatan Pegawaiterhadap Kinerja}

Dari hasil perhitungan analisis jalur, pengaruh langsung keterikatan pegawaiterhadap kinerja pegawai Fakultas Ilmu Sosial dan Ilmu Politik Universitas Indonesia. Dari hasil perhitungan diperoleh nilai koefisien korelasi $r_{23}=0,513$ dan nilai koefisien jalur $p_{32}=0.373$. Hasil penelitian ini dikuatkan oleh pendapatMcShane dan Von Glinow (2013:124) yang menjelaskan, "employee engagement is on the minds of many business leaders these days because it seems to be a strong predictor of employee and work unit performance". Dengan demikian hipotesis 2 yang menduga terdapat pengaruh langsung positif keterikatan pegawaiterhadap kinerja pegawai dapat diterima. Hal ini mencerminkan bahwa penguatanketerikatan pegawai mengakibatkan peningkatankinerja pegawai Fakultas Ilmu Sosial dan Ilmu Politik Universitas Indonesia.

\section{Pengaruh Langsung Work Life Balance terhadap Keterikatan Pegawai}

Dari hasil perhitungan analisis jalur, pengaruh langsung work life balance terhadap keterikatan pegawai Fakultas Ilmu Sosial dan Ilmu Politik Universitas Indonesia. Dari hasil perhitungan diperoleh nilai nilai koefisien korelasi $r_{12}=0,368$ dan nilai koefisien jalur $p_{21}=0.368$. Hasil penelitian ini sesuai dengan penelitian yang dilakukan oleholeh Michael Amstrong (2009:1003) yang menjelaskan, "in addition to fearing the reaction of line managers, the risk of career damage is a common reason for poor take-up of work-life balance arrangements. Line management will need to be convinced that work-life balance measures are important and pay off in terms of increased engagement". Dengan demikian hipotesis 3 yang menduga terdapat pengaruh langsungpositif keterikatan pegawai terhadap keterikatan pegawaidapat diterima. Hal ini mencerminkan bahwa peningkatanwork life balance mengakibatkan penguatanketerikatan pegawai Fakultas Ilmu Sosial dan Ilmu Politik Universitas Indonesia. 


\section{PENUTUP}

Kesimpulan. (1) terdapat pengaruh langsung positif work life balanceterhadap kinerjapegawai, yang ditentukan oleh derajat kekuatan pengaruh dalam bentuk koefisien korelasi dan koefisien jalur. Nilai koefisien jalur ini menentukan seberapa besar varians kinerja pegawaiditentukan oleh variabel work life balance. Selanjutnya dapat diketahui signifikansi pengaruh antara work life balanceterhadap kinerja secara parsial. Hal ini mempunyai makna dan penegasan bahwa work life balancesecara empiris bukan satu-satunya variabel prediktor bagi varians skor kinerja. (2) terdapat pengaruh positif keterikatan pegawaiterhadap kinerjapegawai, yang ditentukan oleh derajat kekuatan pengaruh dalam bentuk koefisien korelasi dan koefisien jalur. Nilai koefisien jalur ini menentukan seberapa besar varians kinerjapegawai ditentukan oleh variabel keterikatan pegawai. Selanjutnya dapat diketahui kekuatan signifikansi pengaruh keterikatan pegawaiterhadap kinerjasecara parsial. Hal ini mempunyai makna dan penegasan bahwaketerikatan pegawaisecara empiris bukan satu-satunya variabel prediktor bagi varians skor kinerja. (3) terdapat pengaruh langsung positif work life balanceterhadap keterikatan pegawai, ditentukan oleh derajat kekuatan pengaruh dalam bentuk koefisien korelasi dan koefisien jalur. Nilai koefisien jalur ini menentukan seberapa besar variansketerikatan pegawaiditentukan oleh variabel work life balance. selanjutnya dapat diketahui signifikansi pengaruh antara work life balancedengan keterikatan pegawai.

Saran. Berdasarkan kesimpulan penelitian disarankan berbagai upaya yang dapat dilaksanakan dalam rangka meningkatkan kinerjapegawai Fakultas Ilmu Sosial dan Ilmu Politik Universitas Indonesia: (1)Hendaknya Rektor sebagai pemimpin tertinggi sekaligus contoh bagi para dosen agar mampu membimbing, mengarahkan serta meningkatkan tanggung jawab serta rasa keterikatan dan kepemilikan yang tinggi terhadap kampus dan sikap peduli terhadap profesi tenaga kependidikan, menciptakan sistem penghargaan yang mampu menghasilkan kualitas pegawai dengan motivasi kerja yang tinggi, patuh terhadap peraturan organiasi, dan sebagai pemimpin harus mampu memperhatikan kesejahteraan para pegawai serta membuat suasana kerja yang nyaman, kondusif, serta mampu membuat kebijakankebijakan yang tidak merugikan pegawainya, mampu mendorong pegawainya untuk bisa menyeimbangkan antara pekerjaan (karir dan ambisi) dan kehidupan (kebahagiaan, waktu luang, keluarga, sosial dan pengembangan spiritual) sehingga mendorong para pegawai untuk bersedia memberikan kesetiaannya dan melakukan tugas melebihi tugas formalnya sebagai pegawai Fakultas Ilmu Sosial dan Ilmu Politik Universitas Indonesia. (2) bagi para pegawai Fakultas Ilmu Sosial dan Ilmu Politik Universitas Indonesia agar memandang bahwa dalam melaksanakan pekerjaannya sebagai pegawai harus memiliki motivasi internal serta kecintaan terhadap pekerjaan yang dijalankan, sehingga pegawai dapat merasakan keikhlasan dan ketulusan terhadap profesi yang diembannya. Pegawai yang keseimbangan pekerjaan dan kehidupan (work-life balance)yang seimbang memberikan kontribusi untuk engagement (keterlibatan pegawai dan komitmen organisasi), yang pada 
gilirannya memberikan kontribusi untuk kinerja yang lebih tinggi dan turn over yang lebih rendah. Selain itu adanya keterikatan terhadap pekerjaan dan organisasi yang tinggi dari seorang pegawai akan melahirkan pegawai yang memiliki kinerja yang tinggi, (3) bagi para peneliti lain agar penelitian ini dapat dijadikan rujukan dalam penelitian lanjutan terkait dengan kinerja pegawai karena ruang lingkup penelitian ini terbatas pada work life balance dan keterikatan pegawai.

\section{DAFTAR RUJUKAN}

Ali Abbaas Albdour Dan Ikhlas I. Altarawneh, "Employee Engagement And Organizational Commitment: Evidence From Jordan", International Journal of Business, 19 (2), 2014

Amstrong Michael, Armstrong's Handbook of Human Resource Management Practice.London: Kogan Page, 2009

Amstrong,Michael Management.New York: John Wiley \& Sons, 2013

Ashtankar OM, "Analysis of the impact of work life balance on wellbeing of police department employees of Nagpur district", International Journal of Applied Research, 2016

Bloombury, Step to Success: Balance Your Life and Work. London: Bloomsbury Publishing Plc, 2005

Byars LIoyrd L. dan Leslie W. Rue, Human Resource Management. New York: McGraw-Hill, 2008

Byars Lloyd L.,Human Resource Management, New York: McGraw-Hill, Irwin, 2011

GibsonJames L., et al., Organizations: Behavior, Structure, Processes. New York: McGraw Hill, 2012

Jason A. Colquitt, Jeffery A. Lepine dan Michael J. Wesson, Organizational Behavior, New York: McGraw Hill, 2013

Jex Steve M., dan Britt Thomas W., Organizational Psychology: A Scientist- Practitioner Approach. New Jersey: John Wiley \& Sons, Inc, 2008

Lewis Suzan dan Cooper Carl L., Work-Life Integration Case Studies of Organizational Change. West Sussex-England: John Wiley \& sons, 2005

Lingard Helen dan Francis Valerie, Managing Work-Life Balance in Construction. New York: Spon Press, 2009

Lockett Katherine, Work/Life Balance for Dummies - Achieve Greater job Satisfaction, Bussienss and Wellbeing Through balancing Your Work and Life. Indianapolis: Wiley Publisihing, 2008 
Mathis Robert 1., dan John H. Jackson, Human Resource management. New York: South-Western Cengage Learning, 2011

McShane dan Glinow Von, Organizational Behavior. New York : McGraw-Hill Book, 2010

McShane dan Glinow Von, Organizational Behavior. New York : McGraw-Hill Book, 2008

Ortiz Daniel Cernas dan Lau Wai Kwan, “The Effect Of Employee Engagement On Continuance And Normative Commitment To The Organization", Management Faculty Research, Maret, 2011.

Poulose Shobitha dan Sudarsan N., "Work Life Balance: A Conceptual Review", International Journal of Advances in Management and Economics, Vol.3, Issue 2, March-April 2014

Robbins Stephen P. dan Judge Timothy A., Organizational Behavior, New York: Pearson, 2013

Robbins Stephen P., dan Coulter Mary, Management. New York : Pearson Education, Inc, 2012

Schermerhorn Jhon R., Management . USA: Jhon Willey and Sons Inc, 2005

Schermerhorn John R., Jr., et al, Organizational Behavior.New York: John Wiley \& Sons, Inc, 2010

Schermerhorn, et al., Organizational Behavior. New York: Pearson Education Inc., 2013

Senthilkumar K.G., et al., "An Empirical Study on Teaching Professionals' Work-Life Balance in Higher Learning Institutions with Special Reference to Namakkal District, Tamilnadu", Bonfring International Journal of Industrial Engineering and Management Science, Vol. 2, No. 3, September 2012 